\title{
The Review
}

\section{Let's reflect:}

\author{
what is the point?
}

After a serious problem in the practice I decided to ask a colleague if they would like to talk, reflect on what had happened, and consider how we could prevent the same again. 'No need for that,' was the reply. 'It has happened now, you can't change the past and we should just move forward.' I walked away reflecting on this quick decisive 'reflection'! Was this doctor representative of many? How would they work through problems in practice? How would this doctor use events to learn and what did this mean for other aspects of personal or professional life? It seems to me that reflection underpins learning from experience ${ }^{1}$ and without this we are surely missing out on an enormous free and important resource.

Reflection goes back a long way. It is thought that Confucius said:

'Study without reflection is a waste of time, Reflection without study is dangerous.

I believe that most doctors don't really embrace reflection and the reason why can be appreciated by considering the learning styles of medical students who are $45 \%$ convergers (practical application) and 21\% accommodators (concrete experience). As a result $66 \%$ do not operate with reflection as their preferred learning style. ${ }^{2}$ This could be you if you like newness, self-discovery, and a 'what if?' approach. By contrast reflectors like insight and a 'why?' approach to make meaning.

Despite these learning styles doctors are being asked repeatedly to demonstrate reflection, in appraisal, training courses, and by the GMC: 'Audit of your own performance, honest self-evaluation, and reflection are the basis of personal development plans in general practice. ${ }^{3}$

Common sense might tell us that reflection for doctors is about using past events to influence future practice. There are, however, many meanings of reflection in education such as 'thinking', 'taking stock', and 'pondering'. Reflective practice is analysed in depth by Dr Jennifer Moon ${ }^{4}$ who describes it as a process of learning from complex situations to give a learning outcome. Sometimes this could lead to transformative learning when we might even change an attitude.

Another way to look at reflection came from Schon ${ }^{5}$ who described it in two ways.
Firstly, 'reflection-in-action' or thinking on your feet and secondly, 'reflection-onaction' perhaps after surgery with colleagues. We all know the most useful reflection happens when talking with colleagues and this is borne out by Hatton and Smith ${ }^{6}$ who found that the best way to help the reflective process was by talking, questioning, or confronting in a safe environment so that self-revelation can take place.

For me reflection promotes selfawareness, personal and professional growth, and makes us more tolerant. Reflection can undoubtedly be a powerful tool when used selectively for learning and an appraisal should be a place for this. However, formalising it and turning it into a summative tool for revalidation will take away the environment and honesty needed. Writing down our reflections may appear to demonstrate our learning to an assessor but this isn't meaningful reflection.

I had trouble finding evidence of the benefits of professionals reflecting through personal development plans. In the Postgraduate Medical Journal Stephen Jennings ${ }^{7}$ quotes evidence that $50 \%$ of GPs regard personal development plans as "hoops to be jumped", and that "their mechanistic production devalues the selfdirected element of formative appraisal'. Furthermore he asks why are health professionals being forced to use personal development plans to "become reflective" when this could demotivate the most selfdirected?'

The educationalists and the revalidation process are turning reflection into a tick box exercise, asking doctors to record reflection so they can demonstrate learning. But does every professional development entry need a reflection? Reflecting on simple things such as why one antibiotic is better than another is more like logical comment with little need for reflection. I would rather have the 'reflection' tab in the new RCGP revalidation e-Portfolio labelled 'comment'. To demonstrate reflection we could write a few longer thoughtful pieces. This would enable better use of reason and emotion which are needed for quality reflection.

Reflection works best when not turned into a chore or tick box exercise. We use this powerful tool everyday in dialogue to make meaning in our most important function, the consultation. It is best used for 'reflection-in-

\section{ADDRESS FOR CORRESPONDENCE}

\section{Jeff Clark}

Nightingale Valley Practice, Brooklea Health Centre, Wick Road, Brislington, Bristol, BS4 4HU UK.

\section{E-mail: jeff.clark@agp-L81033.nhs.uk}

action' or 'reflection-on-action' for situations where there isn't a simple solution. It generates understanding, new ideas, and we should value it rather than killing it with the sword of revalidation.

Real reflection should be complex, imaginative, opening doors, and promoting change.

On reflection what do you think?

\section{Jeff Clark,}

GP and GP Trainer at Nightingale Valley Practice in Bristol and member of the South Bristol GP Trainers Workshop.

uww.southbristolgptrainers.co.uk/

\section{DOI: 10.3399/bjgp11X613232}

\section{REFERENCES}

1. Driessen E, van Tartwijk J, Dornan T. The self critical doctor: helping students become more reflective. BMJ 2008; 336(7648): 827-830.

2. Lynch TG, Woelfl NN, Steele DJ, Hanssen CS Learning style influences student examination performance. Am J Surg 1998; 176(1): 62-66.

3. General Medical Council. Good medical practice. London: GMC, 2006.

4. Moon JA. Reflection in learning and professional development. London: Kogan Page, 1999.

5. Schon DA. The reflective practitioner: how professionals think in action. New York, NY: Basic Books, 1984.

6. Hatton N, Smith D. Reflection in teacher education: towards definition and implementation. Teaching and Teacher Education 1995; 11(1): 33-49.

7. Jennings SF. Personal development plans and self-directed learning for healthcare professionals: are they evidence based? Postgrad Med J 2007; 83 (982): 518-524. 